\title{
Informal Communication in Healthcare (Gossip and Rumour): Nurses' Attitudes
}

\author{
By Serap Bulduk \\ Irem Özel \\ Yeliz Dinçert
}

This study is a descriptive study aimed to determine nurses' attitudes towards gossip and rumour. The study used "The Gossip and Rumour Attitude Scale" developed by Eşkin and Ylldırtm (2013). The scale consists of four sub-scales: identification, causes, effects and reactions. A total of 268 volunteer nurses participated in the study. Data were collected from December 2011 to February 2012. The study found that gossip and rumour occurred due to certain causes, the female nurses in the study tended to believe more than the male nurses that gossip and rumour harmed an organization, the married nurses in the study considered the results of gossip and rumour to be more positive, and, in comparison with the other groups in the study, the nurses in administrative positions considered reactions to gossip and rumour at the expected level according to social rules. In light of these, it is recommended that this study be replicated using a larger sample.

Keywords: Gossip, Health Care, Informal Communication, Rumour, Turkish Nurses.

\section{Introduction}

Organizational culture plays an important role in setting and accomplishing objectives, decisions, strategies, plans and policies within the organization. Organizational culture affects intro-organizational communication and is affected by it (Kiefer 2013, Georganta et al. 2014, Sahin 2010).

Organizational communication includes not only formal (i.e. vertical, horizontal, diagonal) communication, but it also involves informal communication, in which knowledge is communicated within the organization in an informal manner through gossip, rumour and whispers. Informal communication is a spontaneous communication that occurs as a result of interpersonal relations and does not have a specific agenda or purpose. Informal communication does not involve organizational hierarchies and authority status, but it emerges at the organizational level (Özaslan 2009, Sabuncuoğlu and Gümüş 2008). Gossip, which is one of the ways of informal communication, is a natural part of every social environment and has a profound impact on organizations. This is caused by the fact that the communication channels of the informal structure are not formal, it is excessively flexible and its structure resists to eliminate the gossip. The

\footnotetext{
${ }^{*}$ Associate Professor, Düzce University, Turkey.

${ }^{\dagger}$ PhD Student, İstanbul University, Turkey.

\$ Lecturer, Düzce University, Turkey.
} 
organizational grapevine accounts for the environment in which the members of the organization can communicate without needing formal rules and thus it is the most appropriate environment for gossip to spread (Akdoğan et al. 2009).

Technically, any trivial or unproven information sharing can be accepted as gossip. Gossip has two distinct impacts: a positive impact and a negative impact (Abbajay 2013, Georganta et al. 2014, Kiefer 2013). Positive gossip involves functions such as staff getting social satisfaction (e.g. personal friendships, informal groups, etc.) and often completion of unknown or missing information (Baumeister et al. 2004, Sommerfeld et al. 2007). In addition, in comparison with formal channels, it informal communication ensures more rapid dissemination of information (Oğuz 2001, Özaslan 2009). It also helps managers find out about employees' various complaints and suggestions about the organization and its environment in a short time, take the necessary measures, and prevent organizational losses (Tutar et al. 2004). It was reported that positive effects of gossip is seen higher at an individual level than a group level (Ellwardt et al. 2012).

Gossip can have many adverse side effects on an organization. Gossip can give rise to organizational conflicts and it can reduce employee's motivation. The sense of trust within the group can be reduced due to these strained relations. In this case, managers have to spend a large portion of their time to manage the consequences of gossip and to develop a perception that "they cannot manage their teams appropriately" (Abbajay 2013). Therefore, it is essential that the presence of informal communication can be recognized and necessary measures can be taken so that its potential negative impact on organizational order and individuals can be eliminated (Sabuncuoğlu and Gümüs 2008). It is possible to regard gossip with a negative characteristic as bullying, particularly if there are lies involved. Most of the bullying encountered in adult population takes place as relational aggression, and it takes the shape of rumor, gossip and hearsay. This ruins the reputation of individuals and also the interpersonal climate it brings about will have distrust and ill will, which is not a suitable condition to work and establish social ties (Kiefer 2013).

The hospital setting, which is a high-stress work environment, increases the amount of gossip shared. Gossip is said to be a normative aspect of work. As a result, burnout and engagement feelings improve the influence of gossip on attitudes related to care. Gossip may particularly help relax in some emotional situations that occur in multi-directional relationships with patients or other colleagues. Gossip critically affects healthcare given on a daily basis and has a direct impact on healthcare staff, especially on nurses. Waddington and Fletcher (2005) report that nurses use gossip as a way of emotional support and a tool of coping with stress in profound emotions they usually experience with patients and other colleagues. Unmanaged gossip can have a negative effect on the relationships in the workplace and damage the organization's reputation. For an active management of gossip, nurses, as the primary care givers in the hospital setting, can play a proactive role in developing strategies to effectively control gossip (Thomas and Rozelle 2007). 
On the other hand, despite its negative reputation in general, gossip continues to be an important type of communication in every community. Gossip serves three primary functions: information, influence or social control, and entertainment. Also, gossip may contribute to the socialization of nurses and to the functions related to their professional role (Laing 1993). In light of this, the aim of this descriptive study is to determine the attitudes of nurses working in the hospitals in Turkey towards gossip and rumour.

\section{Method}

\section{Population and Sample}

The study population consisted of a total of 418 nurses working in two private and two public hospitals. The study sample, however, included a total of 272 nurses who were trained as nurses, health officers and emergency medical technicians, who were working as nurses, and who were willing to participate in the study. These professionals were considered in the same group because their training programs were similar and their tasks within the institutions were described as nurses. However, the nurses who refused to participate in the study, who did not return the questionnaires, or who returned the questionnaires with missing or incomplete data were excluded from the study. Therefore, the study sample consisted of a total of 268 nurses.

\section{Data Collection Tools}

Questionnaire: The study used a questionnaire containing 16 questions about the socio- demographic and institutional characteristics of the nurses.

The Gossip and Rumour Attitude Scale (GRAS): The study also used "the Gossip and Rumour Attitude Scale" developed by Eşkin and Yıldırım (2013). The scale consists of four sub-scales: identification, causes, effects and reactions. The scale uses a 5-point Likert-type scale measuring the participants' level of agreement with a given statement ranging from 1 (strongly disagree) to 5 (strongly agree). According to the scale, certain items require reverse coding. Depending on the options chosen by the participants, the means were calculated through dividing the total score of the item in each of the sub-scales by the number of items in the corresponding sub-scale. Therefore, the lowest and highest possible scores of the sub-scales range between "1" and "5". Since the GRAS is a multidimensional sub-scale, the mean scores of the sub-scales were assessed separately and no analyses were carried out on the total score mean of the scale. The explanations regarding the sub-scales are presented below.

Lower mean scores on the identification sub-scale indicate that respondents have negative attitudes towards gossip and rumour whereas higher mean scores on this sub-scale indicate that respondents have positive attitudes towards gossip and rumour. 
Lower mean scores on the causes sub-scale indicate that respondents believe gossip and rumours cannot be attributed to any cause while higher mean scores on this sub-scale indicate that respondents believe gossip and rumours occur due to certain causes.

Lower mean scores on the effects sub-scale indicate that respondents believe the personal and organizational effects of gossip and rumour are negative whereas higher mean scores on this sub-scale indicate that respondents believe the personal and organizational effects of gossip and rumour are positive.

Finally, lower mean scores on the reactions sub-scale indicate that the magnitude of individuals' reactions is above the expected level while higher mean scores on this sub-scale indicate that the magnitude of individuals' reactions is at the expected level (Eşkin and Y1ldırım 2013).

\section{Data Analysis}

All the statistical analyses were performed using SPSS 16.0 statistical software package. Data were evaluated by using percentage, t-test, MannWhitney U test, Analysis of Variance (ANOVA) and the Kruskal-Wallis test. Descriptive statistics about all data were presented by means of Mean \pm Standard Deviation $(\mathrm{x} \pm \mathrm{SD})$ and percentage $(\%)$. The $\mathrm{p}$-value for statistical significance was defined as $\mathrm{p}<0.05$.

\section{Ethical Considerations}

During the planning phase of the study, F. Eşkin, who performed the validity and reliability tests of the Gossip and Rumour Attitude Scale, was contacted via e-mail, and written permission to use the scale was obtained. Also, written permissions were obtained from the administrations of the hospitals where the groups in the study sample were formed. All the individuals participating in the study were informed about the study objective, they were explained about the extent of the use of data, and their verbal consents were obtained. The study was conducted in compliance with the Helsinki Declaration of Principles.

\section{Results}

The results from this study are presented according to certain sociodemographic variables and gossip among the nurses.

The mean age of the nurses surveyed was $28.53 \pm 5.88,58.2 \%$ of the nurses $(\mathrm{N}=156)$ were married, $40.6 \%(\mathrm{~N}=109)$ had an undergraduate degree, $39.6 \%$ $(\mathrm{N}=106)$ had work experience less than 1 year, and $60.1 \%(\mathrm{~N}=191)$ had previously worked in another institution, $72.8 \%(\mathrm{~N}=195)$ worked as nurses, $68.7 \%$ CPC $(\mathrm{N}=184)$ had clearly defined job descriptions in their institutions/units, and 53\% ( $\mathrm{N}=142)$ were not given orientation training. Also, 
$88.1 \%(\mathrm{~N}=236)$ of the nurses in the study thought there was gossip in their institutions, they believed that those who gossiped most at workplace were nurses (52.6\%), non-healthcare workers (47\%), physicians (37.3\%), administrators $(35.8 \%)$ and others $(15.7 \%)$.

Table 1. Difference among the Sub-Scales of the Gossip and Rumour Attitude Scale according to the Types of Institutions

\begin{tabular}{|l|c|c|c|c|}
\hline \multirow{2}{*}{ Sub-scales } & $\begin{array}{c}\text { State } \\
(\mathbf{N}=\mathbf{1 5 9})\end{array}$ & $\begin{array}{c}\text { Private } \\
(\mathbf{N}=\mathbf{1 0 9})\end{array}$ & $\mathbf{t}$ & $\mathbf{p}$ \\
\cline { 2 - 3 } & $\mathbf{X} \pm \mathbf{S D}$ & $\mathbf{X} \pm \mathbf{S D}$ & & \\
\hline Identification & $2.31 \pm 0.59$ & $2.29 \pm 0.05$ & 0.271 & 0.787 \\
\hline Causes & $3.79 \pm 0.54$ & $3.51 \pm 0.68$ & $\mathbf{3 . 7 0 8}$ & $\mathbf{0 . 0 0 0}$ \\
\hline Effects & $1.85 \pm 0.60$ & $2.08 \pm 0.76$ & $\mathbf{- 2 . 8 3 1}$ & $\mathbf{0 . 0 0 5}$ \\
\hline Reactions & $2.72 \pm 0.60$ & $2.74 \pm 0.76$ & $\mathbf{- 0 . 1 4 8}$ & 0.883 \\
\hline
\end{tabular}

According to the nurses' attitudes about gossip and rumour with respect to the type of the institution where they worked, there was a significant difference between the causes and effects subscales $(\mathrm{p}<0.05)$. This result indicates that the nurses who worked in the state hospitals tended to believe more than those working in the private hospitals that gossip and rumour occurred due to certain reasons. On the other hand, the nurses working in the private hospitals tended to believe more than those working in the state hospitals that the effects of gossip and rumours could be positive (Table 1).

Table 2. Difference among the Sub-scales of the Gossip and Rumour Attitude Scale according to Gender Variable

\begin{tabular}{|l|c|c|c|c|}
\hline \multirow{2}{*}{ Sub-scales } & $\begin{array}{c}\text { Female } \\
(\mathbf{N = 2 2 6})\end{array}$ & $\begin{array}{c}\text { Male } \\
\mathbf{( N = 4 2 )}\end{array}$ & \multirow{2}{*}{$\mathbf{Z}_{\mathbf{M U}}$} & \\
\cline { 2 - 3 } & $\mathbf{X} \pm$ SD & $\mathbf{X} \pm$ SD & & \\
\hline Identification & $2.30 \pm 0.58$ & $2.30 \pm 0.58$ & -0.061 & 0.952 \\
\hline Causes & $3.65 \pm 0.62$ & $3.83 \pm 0.57$ & -1.430 & 0.153 \\
\hline Effects & $1.99 \pm 0.67$ & $1.68 \pm 0.67$ & $-\mathbf{3 . 1 6 0}$ & $\mathbf{0 . 0 0 2}$ \\
\hline Reactions & $2.73 \pm 0.65$ & $2.70 \pm 0.74$ & -0.438 & 0.661 \\
\hline
\end{tabular}

According to the nurses' attitudes about gossip and rumour according to gender, there was a significant difference in the favour of the female on the effects sub-scale $(p<0.05)$. This result suggests that the female nurses in the study tended to believe more than the male nurses that the effects of gossip and rumour scould be positive (Table 2). 
Table 3. Difference among the Sub-scales of the Gossip and Rumour Attitude Scale according to Marital Status

\begin{tabular}{|l|c|c|c|c|}
\hline \multirow{2}{*}{ Sub-scales } & $\begin{array}{c}\text { Single } \\
(\mathbf{N}=\mathbf{1 0 4})\end{array}$ & $\begin{array}{c}\text { Married } \\
(\mathbf{N}=\mathbf{1 5 6})\end{array}$ & $\mathbf{t}$ & $\mathbf{p}$ \\
\cline { 2 - 3 } & $\mathbf{X} \pm \mathbf{S D}$ & $\mathbf{X} \pm \mathbf{S D}$ & & \\
\hline Identification & $2.37 \pm 0.55$ & $2.28 \pm 0.61$ & 1.221 & 0.223 \\
\hline Causes & $3.61 \pm 0.62$ & $3.70 \pm 0.62$ & -1.193 & 0.234 \\
\hline Effects & $1.90 \pm 0.67$ & $1.98 \pm 0.69$ & -0.971 & 0.332 \\
\hline Reactions & $2.79 \pm 0.68$ & $2.69 \pm 0.65$ & 1.185 & 0.237 \\
\hline
\end{tabular}

There was no significant difference among the subscales according to the nurses' attitudes about gossip and rumours according to their marital status (p>0.05) (Table 3).

Table 4. Difference among the Sub-scales of the Gossip and Rumour Attitude Scale according to Education Level

\begin{tabular}{|c|c|c|c|c|c|c|}
\hline \multirow[t]{2}{*}{ Sub-scales } & $\begin{array}{c}\text { High } \\
\text { School } \\
(\mathrm{N}=106)\end{array}$ & $\begin{array}{l}\begin{array}{l}2 \text {-year } \\
\text { College } \\
(\mathrm{N}=46)\end{array} \\
\end{array}$ & $\begin{array}{l}\text { Undergraduate } \\
\quad(N=109)\end{array}$ & $\begin{array}{c}\text { Graduate } \\
\quad(N=7)\end{array}$ & \multirow[t]{2}{*}{$\mathbf{X}_{K W}$} & \multirow[t]{2}{*}{$\mathbf{p}$} \\
\hline & $\mathrm{X} \pm \mathrm{SD}$ & $\mathbf{X} \pm \mathrm{SD}$ & $\mathrm{X} \pm \mathrm{SD}$ & $\mathrm{X} \pm \mathrm{SD}$ & & \\
\hline Identification & $2.24 \pm 0.63$ & $2.35 \pm 0.54$ & $2.33 \pm 0.56$ & $2.49 \pm 0.41$ & 3.330 & 0.343 \\
\hline Causes & $3.67 \pm 0.66$ & $3.44 \pm 0.67$ & $3.74 \pm 0.51$ & $4.24 \pm 0.46$ & 14.100 & 0.003 \\
\hline Effects & $1.88 \pm 0.70$ & $2.16 \pm 0.73$ & $1.93 \pm 0.63$ & $1.71 \pm 0.56$ & 7.910 & 0.048 \\
\hline Reactions & $2.68 \pm 0.70$ & $2.73 \pm 0.82$ & $2.77 \pm 0.57$ & $2.84 \pm 0.55$ & 1.600 & 0.659 \\
\hline
\end{tabular}

According to the nurses' attitudes about gossip and rumours according to their education level, there was a significant difference on the causes and effects sub-scales $(p<0.05)$. The nurses who were two-year college graduates were more inclined to believe that the effects of gossip and rumours could be positive. On the other hand, the nurses who had a graduate degree tended to believe more than the other groups that gossip and rumours occurred due to certain reasons (Table 4).

Table 5. Difference among the Sub-scales of the Gossip and Rumour Attitude Scale according to Duration of Work Experience

\begin{tabular}{|l|c|c|c|c|c|c|}
\hline Sub-scale & $\begin{array}{c}\text { Less than 1 } \\
\text { year } \\
(\mathbf{N = 1 0 6})\end{array}$ & $\begin{array}{c}\mathbf{1 - 3} \text { years } \\
(\mathbf{N = 7 6})\end{array}$ & $\begin{array}{c}\mathbf{4 - 8} \text { years } \\
(\mathbf{N = 5 2})\end{array}$ & $\begin{array}{c}\text { 9 years or } \\
\text { longer } \\
(\mathbf{N}=\mathbf{3 4})\end{array}$ & $\mathbf{F}$ & $\mathbf{p}$ \\
\cline { 2 - 7 } $\mathbf{X} \pm \mathbf{S D}$ & $\mathbf{X} \pm \mathbf{S D}$ & $\mathbf{X} \pm \mathbf{S D}$ & $\mathbf{X} \pm \mathbf{S D}$ & & \\
\hline Identification & $2.30 \pm 0.56$ & $2.23 \pm 0.63$ & $2.45 \pm 0.57$ & $2.23 \pm 0.55$ & 1.595 & 0.191 \\
\hline Causes & $3.54 \pm 0.65$ & $3.78 \pm 0.59$ & $3.74 \pm 0.61$ & $3.75 \pm 0.49$ & $\mathbf{2 . 9 2 0}$ & $\mathbf{0 . 0 3 5}$ \\
\hline Effects & $1.98 \pm 0.76$ & $1.86 \pm 0.75$ & $1.95 \pm 0.52$ & $1.98 \pm 0.44$ & 0.502 & 0.681 \\
\hline Reactions & $2.78 \pm 0.74$ & $2.68 \pm 0.61$ & $2.66 \pm 0.66$ & $2.78 \pm 0.59$ & 0.611 & 0.609 \\
\hline
\end{tabular}

According to the nurses' attitudes about gossip and rumours according to their duration of work experience, there was a significant difference on the causes sub-scale in favour of those nurses with a work experience of 1-3 years $(p<0.05)$. The nurses who had a work experience of 1-3 years tended to believe 
more than the other groups that gossip and rumours occurred due to certain reasons (Table 5).

Table 6. Difference among the Sub-scales of the Gossip and Rumours Attitude Scale according to Position at the Workplace

\begin{tabular}{|c|c|c|c|c|c|}
\hline \multirow[t]{2}{*}{ Sub-scale } & $\begin{array}{c}\text { Nurse } \\
(\mathrm{N}=195)\end{array}$ & $\begin{array}{c}\text { Administrator } \\
(\mathrm{N}=39)\end{array}$ & $\begin{array}{l}\text { Other } \\
(\mathrm{N}=34)\end{array}$ & \multirow[t]{2}{*}{$\mathbf{X}_{\mathbf{K W}}$} & \multirow[t]{2}{*}{$\mathbf{P}$} \\
\hline & $\mathrm{X} \pm \mathrm{SD}$ & $\mathbf{X} \pm \mathrm{SD}$ & $\mathrm{X} \pm \mathrm{SD}$ & & \\
\hline Identification & $2.33 \pm 0.61$ & $2.31 \pm 0.46$ & $2.14 \pm 0.53$ & 3.096 & 0.213 \\
\hline Causes & $3.67 \pm 0.62$ & $3.61 \pm 0.70$ & $3.79 \pm 0.45$ & 1.614 & 0.446 \\
\hline Effects & $1.95 \pm 0.69$ & $2.14 \pm 0.71$ & $1.67 \pm 0.48$ & 8.233 & 0.016 \\
\hline Reactions & $2.69 \pm 0.65$ & $3.04 \pm 0.71$ & $2.60 \pm 0.61$ & 9.518 & 0.009 \\
\hline
\end{tabular}

According to the nurses' attitudes about gossip and rumour according to their position at the workplace, there was a significant difference on the effects and reactions sub-scales $(\mathrm{p}<0.05)$. This result revealed that the participants in administrative positions were more prone than the other groups to believe that the effects of gossip and rumour could be positive. The participants in administrative positions also considered reactions to gossip and rumour at the expected level (Table 6).

Table 7. Difference among the Sub-scales of the Gossip and Rumour Attitude Scale according to Having Clear Job Descriptions

\begin{tabular}{|l|c|c|c|c|}
\hline Sub-scale & $\begin{array}{c}\text { Yes } \\
(\mathbf{N = 1 8 4})\end{array}$ & $\begin{array}{c}\text { No } \\
(\mathbf{N = 8 4})\end{array}$ & $\mathbf{t}$ & $\mathbf{p}$ \\
\cline { 2 - 3 } & $\mathbf{X} \pm \mathbf{S D}$ & $\mathbf{X} \pm \mathbf{S D}$ & & \\
\hline Identification & $2.36 \pm 0.58$ & $2.18 \pm 0.57$ & $\mathbf{2 . 3 4 2}$ & $\mathbf{0 . 0 2 0}$ \\
\hline Causes & $3.65 \pm 0.62$ & $3.74 \pm 0.60$ & -1.095 & 0.275 \\
\hline Effects & $1.98 \pm 1.98$ & $1.87 \pm 0.65$ & 1.229 & 0.220 \\
\hline Reactions & $2.75 \pm 0.67$ & $2.69 \pm 0.66$ & 0.609 & 0.543 \\
\hline
\end{tabular}

According to the nurses' attitudes about gossip and rumours according to having clear job descriptions, there was a significant difference on the identification sub-scale in favour of those nurses who worked in institutions not providing clear job descriptions $(\mathrm{p}<0.05)$. This result suggest that the nurses who worked in institutions providing clear job descriptions were more prone to having positive attitudes towards identifying gossip and rumours (Table 7).

There was no significant difference among the subscales according to the nurses' attitudes about gossip and rumour according to receiving orientation training ( $>0.05)$ (Table 8). 
Table 8. Difference among the Sub-scales of the Gossip and Rumour Attitude Scale according to Receiving Orientation Training

\begin{tabular}{|l|c|c|c|c|}
\hline \multirow{2}{*}{ Sub-scale } & $\begin{array}{c}\text { Yes } \\
(\mathbf{N = 1 2 6})\end{array}$ & $\begin{array}{c}\text { No } \\
(\mathbf{N = 1 4 2})\end{array}$ & $\mathbf{t}$ & $\mathbf{p}$ \\
\cline { 2 - 3 } & $\mathbf{X} \pm \mathbf{S D}$ & $\mathbf{X} \pm$ SD & & \\
\hline Identification & $2.29 \pm 0.57$ & $2.31 \pm 0.60$ & -0.371 & 0.711 \\
\hline Causes & $3.62 \pm 0.64$ & $3.72 \pm 0.59$ & -1.298 & 0.195 \\
\hline Effects & $1.97 \pm 0.72$ & $1.91 \pm 0.65$ & 0.596 & 0.552 \\
\hline Reactions & $2.73 \pm 0.73$ & $2.72 \pm 0.61$ & 0.131 & 0.896 \\
\hline
\end{tabular}

\section{Discusssion}

Is it possible for one not to gossip or to be the subject of others' gossip? Gossip and rumour is like a social virus which people cannot develop immunity against. In the field of healthcare, especially clinics, hospitals, and nursing homes are among the areas where gossip takes place most. It is shown that negative gossip in hospital environment is related to burnout, emotional exhaustion and depersonalization (Georganta et al. 2014). If gossip cannot be managed properly, it can lead to the deterioration of professional relations in the field of healthcare and it may even harm the patient. Strong professional relationships in healthcare are as important as the patient's treatment. Particularly patient safety and optimal care might be negatively affected by gossip (Georganta et al. 2014). This is because the patient can feel the tension between those who provide healthcare services (Waddington and Fletcher 2005). For nurses, who are the primary care givers in healthcare, their patients are a top priority and, in this sense, patient care is a service that requires complete attention. It is hard for a nurse who is curious about what others talk about him or her to focus on patients. Also, nurses can play a proactive role in developing strategies to effectively control gossip.

Gossip is believed to occur often due to what people do not have full knowledge of but are curious about. In organizational terms, the presence of gossip in any organization indicates that organizational tasks are not clearly defined and there is a structural defect. In this regard, the fact that the vast majority of the nurses in the study thought that there was gossip in their workplaces could be due to the lack of clearly defined job descriptions and/or other organizational problems (Georganta et al. 2014, Kiefer 2013). In fact, as a result of the rapid development of some other areas of healthcare as well as patient care and increasing diversity of tasks, nurses are also supposed to perform non-nursing tasks (Ünal and Seren 2010). Aslan (2013) suggested that lack of clear job descriptions in hospitals is perceived as a cause of conflict, lack of balance between powers and responsibilities lead to conflicts within institutions, and younger nurses feel these conflicts more severely. The result that the vast majority of the participants believed that there was gossip in their workplaces indicates that the institutionalization of hospitals and nursing services is yet to be developed. Waddington and Fletcher (2005) found that 
gossip acts as a means of expressing feelings of anger, restlessness, anxiety and concern. On the other hand, this emotional context creates threats and opportunities for organizations and individuals at the same time.

Another factor affecting the perception that gossip occurs due to certain causes is the individuals' educational background. In fact, in our study, the nurses who had a graduate degree tended to believe more than the other groups that gossip occurred due to certain reasons and it had negative effects. This result suggests that the nurses with graduate degrees had higher levels of awareness about the causes of the emergence of gossip than the nurses with different levels of education. On the other hand, in Turkey, differences among nurses' educational levels are evident and especially the proportion of nurses who have completed a graduate degree is quite low. It is possible that particularly the nurses with graduate degrees in this study made more accurate analysis about the causes of the emergence of gossip in their institutions and they had higher levels of awareness about the issue. This suggestion implies that these nurses can play a key role in gossip management.

In this study, the nurses who had a work experience of 1-3 years tended to believe more than the other groups that gossip and rumour occurred due to certain reasons. Gossip and rumour are effective in imparting meaning to uncertain events of the present and the future. In this way, individuals try to make sense of the events related to their jobs and be prepared for them by filling the information gap concerning their duties and responsibilities, because cultural learning is enhanced to a great extent through gossip. The reason for this is that people may get help from experiences of people who are not visible to a person and are not even among that person's friends (Baumeister et al. 2004). Therefore, since nurses with 1-3 years of job experience or in other words those who have entered working environment recently are inexperienced, their tendency to engage in gossip is high in order to get familiar with organizational culture and evaluate the events in the organization (Solmaz 2013).

In our study, the female nurses, the nurses working in the private hospitals, the nurses in administrative positions, and the nurses working in the hospitals providing clear job descriptions had more positive perceptions about the effects of gossip. In fact, the literature reports that gossip do have some positive effects. For example, by means of gossip, individuals working outside of the hierarchical structure of an organization meet their social needs when they come together in various environments and gossip gives organizational activities speed and efficiency (Eroğlu 2005). In this study, the female nurses had more positive attitudes towards gossip probably because gossip has a social dimension involving feelings of friendship and collaboration. Thus, it is stated in the literature that gossip relationsis stronger for women (Georganta et al. 2014). Moreover, it was found out that individuals tend to show more interest to people and information from their own gender (Watson 2012).

The study also found that the nurses in administrative positions had more positive opinions about gossip and they considered reactions to gossip and rumour at the expected level. This result suggests that gossip and rumours are 
considered as important means of collecting information. Gossip functions as a strong tool to control society informally, and groups in the society and their norms are preserved by this (Georganta et al. 2014). In fact, nurses are believed to regard gossip, which makes it possible to communicate information among employees, estimate employees' reactions to new administrative initiatives, make predictions about administrators' behaviours provide information concerning organizational preparedness and employee behaviour and facilitate sharing feelings about relationships with patients, as a significant managerial tool (Thomas and Rozelle 2007). However, that the manager conducts gossip in formal or informal ways may give us different information as to this institution. Taking into account that hospitals are institutions which have hierarchical cultures, gossip might be the only way for such cultures to gain information (Lentza et al. 2014). Even if it is to be used as a managerial tool rather than for malicious purposes, it is necessary that both its content and the area it spreads is controlled well.

The study found that the nurses who worked in institutions providing clear job descriptions were more prone than the other groups to have positive attitudes towards identifying gossip and rumours. Describing duties and responsibilities is clearly extremely important in terms of establishing coordination within institutions, creating unity of goals in achieving the organizational objectives and creating organizational transparency (Ekici 2013). The presence of positive attitudes among the nurses towards identifying gossip and rumour in hospitals where duties and responsibilities were clearly defined could have created a sense of willingness to avoid risks and threats (e.g. gossip and rumour) against the existing system. On the other hand, in terms of a systems approach, the same result implies a model that is known as open/closed systems view and can be applied into the hospital setting. Systems in which duties and responsibilities are clearly described are defined as open systems. Open systems continuously interact with their environments, receive input from their environments and modify these inputs as outputs. Closed systems, on the other hand, tend to sustain themselves, do not interact with their environments, and exhibit a static structure. Therefore, closed systems are less sensitive to environmental changes (Yalçınkaya 2002). In the light of this, the presence of positive attitudes towards identifying gossip and rumour received from the environment in hospitals providing clear job descriptions could be due to the fact that these institutions had an organizational structure based on open systems.

\section{Conclusion and Recommendations}

In this study, nurses were selected as a rich source of information. Therefore, the findings only reflect the culture and practice of professional nursing in Turkey. Future research can be extended to include healthcare organizational roles and perspective so that feelings and relationship dynamics and details about starting and sustaining gossip can be investigated. 
Furthermore, it is recommended for future studies that whether gossip occurs among male health workers in different ways is determined.

The study found that the nurses working in the state and private hospitals were severely affected by gossip. This result showed that particularly nurses in administrative positions play a key role in the management of gossip. Based on the notion that organization is a social system, it is recommended that administrators accept that it is not possible to prevent gossip and that they should develop strategies to better manage it. In this sense, it is recommended that an adequate communication system should be created in institutions and this communication system should be able to provide each individual with at least two direct communication ways. In addition, apart from correspondence and reports, administrators can make communication more efficient by using methods such as meetings, small group meetings, and training seminars to ensure face-to-face communication. "Open door" policy can save managers time.

\section{References}

Aslan Ş (2013) Hastanelerde örgütsel çatışma: teori ve örnek bir uygulama (Organizational conflict at hospitals: theory and a sample implementation). Jan. Retrieved from http://goo.gl/48Ajeo.

Akdoğan AA, Mirap S, Cingöz A (2009) İşgörenlerin Dedikoduya Inanma Düzeyleri ve Dedikodunun Amaçlarına Ilişkin Algılamaları, Örgütsel ve Bireysel Değişiklikler Açısından Bir Inceleme (The Levels of Employees' Belief in Gossip and Their Perceptions of The Aims of Gossip, A Study in Organizational and Individual Changes). National Management and Organization Congress, Book of Proocedings, 17-25.

Abbajay M (2013) The danger of workplace gossip. Nov. Retrieved from http://goo.gl/W7S8Jn.

Baumeister RF, Zhang L, Vohs KD (2004) Gossip as cultural learning. Review of General Psychology 8(2): 111-121.

Eşkin F, Yıldırım A (2013) Dedikodu ve söylenti tutum ölçeği’nin geliştirilmesi (Development of the Gossip and Rumor Attitude Scale). Anadolu Hemşirelik ve Sağllk Bilimleri Dergisi 16: 36-42.

Ekici D (2013) Sağllk Bakım Hizmetinin Yönetimi (Management of Health Care Services). Ankara: Sim Matbaacilık.

Ellwardt L, Wittek R, Wielers R (2012) Talking about the boss: effects of generalized and interpersonal trust on workplace gossip. Group \& Organization Management 37: 521-549.

Eroğlu E (2005) Yöneticilerin dedikodu ve söylentiye yönelik davranış biçimlerinin belirlenmesi -Arfor Taşıma Hizmetleri A.Ş.'de Bir Uygulama) (Determination of behavioral patterns of managers towards gossip and rumor-An implementation at Arfor Taşıma Hizmetleri A.Ş.). Journal of Social Sciences 13: 203-218.

Georganta K, Panagopoulou E, Montgomery A (2014) Talking behind their backs: negative gossip and burnout in hospitals. Burnout Research 1: 76-81.

Kiefer CC (2013) Rumors and gossip as forms of bullying: sticks and Stones. Psychoanalytic Inquiry 33: 90-104. 
Laing M (1993) Gossip: Does it play a role in the socialization of nurses? Journal of Nursing Scholarship 25: 37-44.

Lentza V, Montgomery AJ, Georganta K, Panagopoulou E (2014) Constructing the health care system in Greece: responsibility and powerlessness. The British Psychological Society 19: 219-230.

Özaslan S (2009) Sözsüz Iletişimin Örgütsel Iletişim Tatminine Etkileri: Çanakkale'deki Konaklama İşletmelerine Yönelik Bir Araştırma (The Effects of Nonverbal Communications on Satisfaction of Organizational Communication: A Study about Accommodation Establishments in Çanakkale). Master Thesis. Social Sciences Instititute the Department of Tourism Management, Çanakkale Onsekiz Mart University, Çanakkale.

Oğuz B (2001) Örgütsel İletişim ve Önemi (Organizational Communication and Its Importance). Master Thesis. Social Sciences Institute, Marmara University, İstanbul.

Sommerfeld RD, Krambeck H-J, Semmann D, Milinski M (2007) Gossip as an alternative for direct observation in games of indirect reciprocity. Proceedings of the National Academy of Sciences of the United States of America 10: 17435-17440.

Sabuncuoğlu Z, Gümüş M (2008) Örgütlerde İletişim (Communication in Organizations). Arıkan Basın Yayım, İstanbul.

Şahin A (2010) Örgüt kültürü-yönetim ilişkisi ve yönetsel etkinlik (The Relationship Between Organizational Culture-Management and Efficiency of Managerial). Maliye Dergisi 159: 21-35.

Solmaz B (2013) Söylenti ve dedikodu yönetimi (Management of rumor and gossip). Jan. Retrieved from http://goo.gl/2FK0It.

Tutar H, Yılmaz MK, Erdönmez C (2004) Genel ve Teknik İletişim (General ve Technical Communication). (2nd Edn). Nobel Yayın Dağıtım, Ankara.

Thomas SA, Rozell EJ (2007) Gossip and nurses malady or remedy?. The Health Care Manager 26: 111-115.

Ünal A, Seren Ş (2010) Hastanelerde çalışan hemşirelerin hemşirelik dışı birimlerde istihdamı ve nedenlerinin incelenmesi (Employment of nurses in non-nursing departments and evaluation of causes). DEUHYO Dergisi 3: 23-29.

Waddington K, Fletcher C (2005) Gossip and emotion in nursing and health-care organizations. Journal of Health Organization and Management 19: 378-394.

Watson DC (2012) Gender differences in gossip and friendship. Sex Roles 67(9): 494502.

Yalçınkaya M (2002) Açık sistem teorisi ve okulda uygulanması (The open system theory and its applications to school). Gazi Eğitim Fakültesi Dergisi 22: 103-116. 